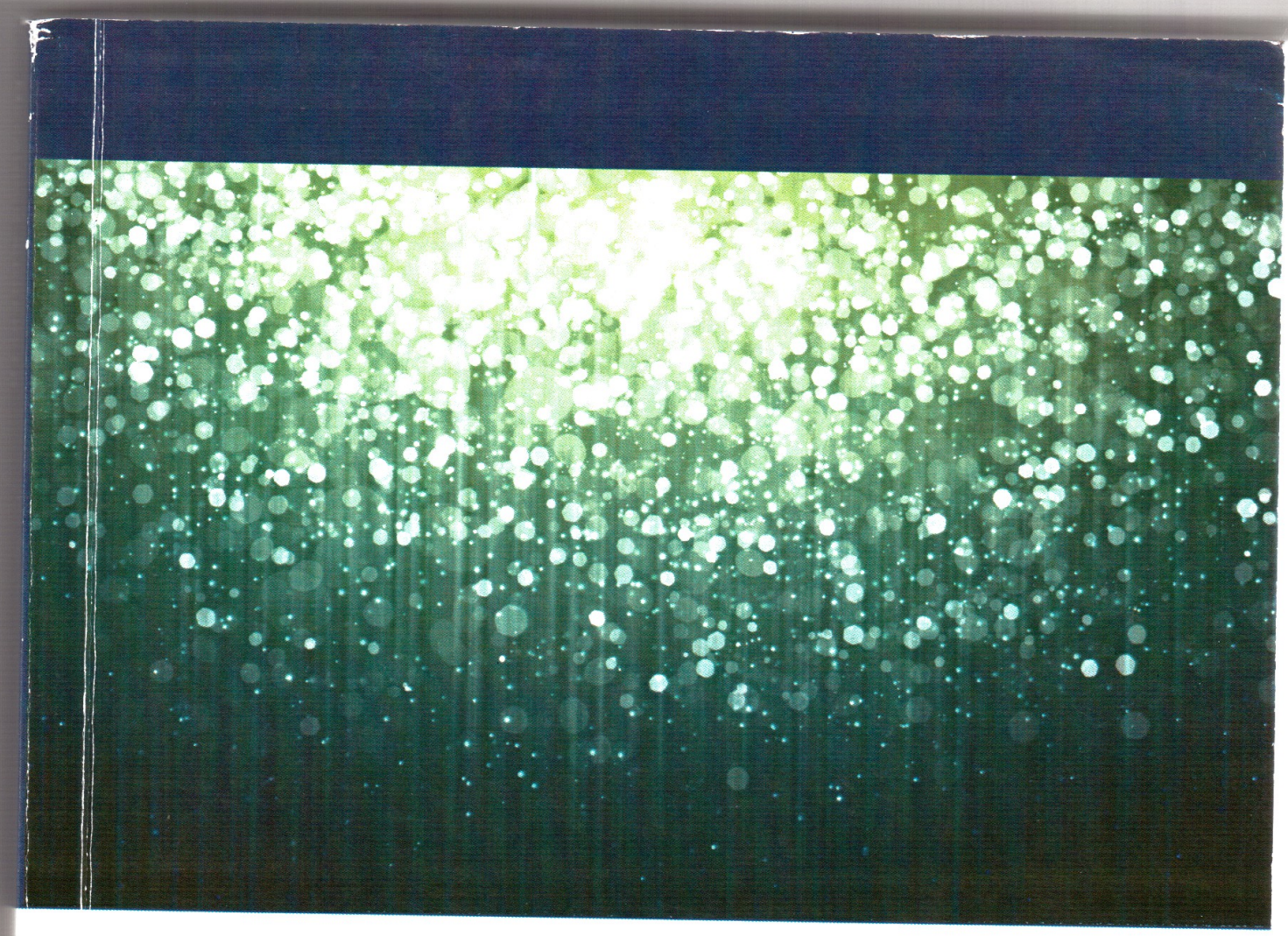

Абдуманап Абдураманов

\title{
Механика жидкости
}




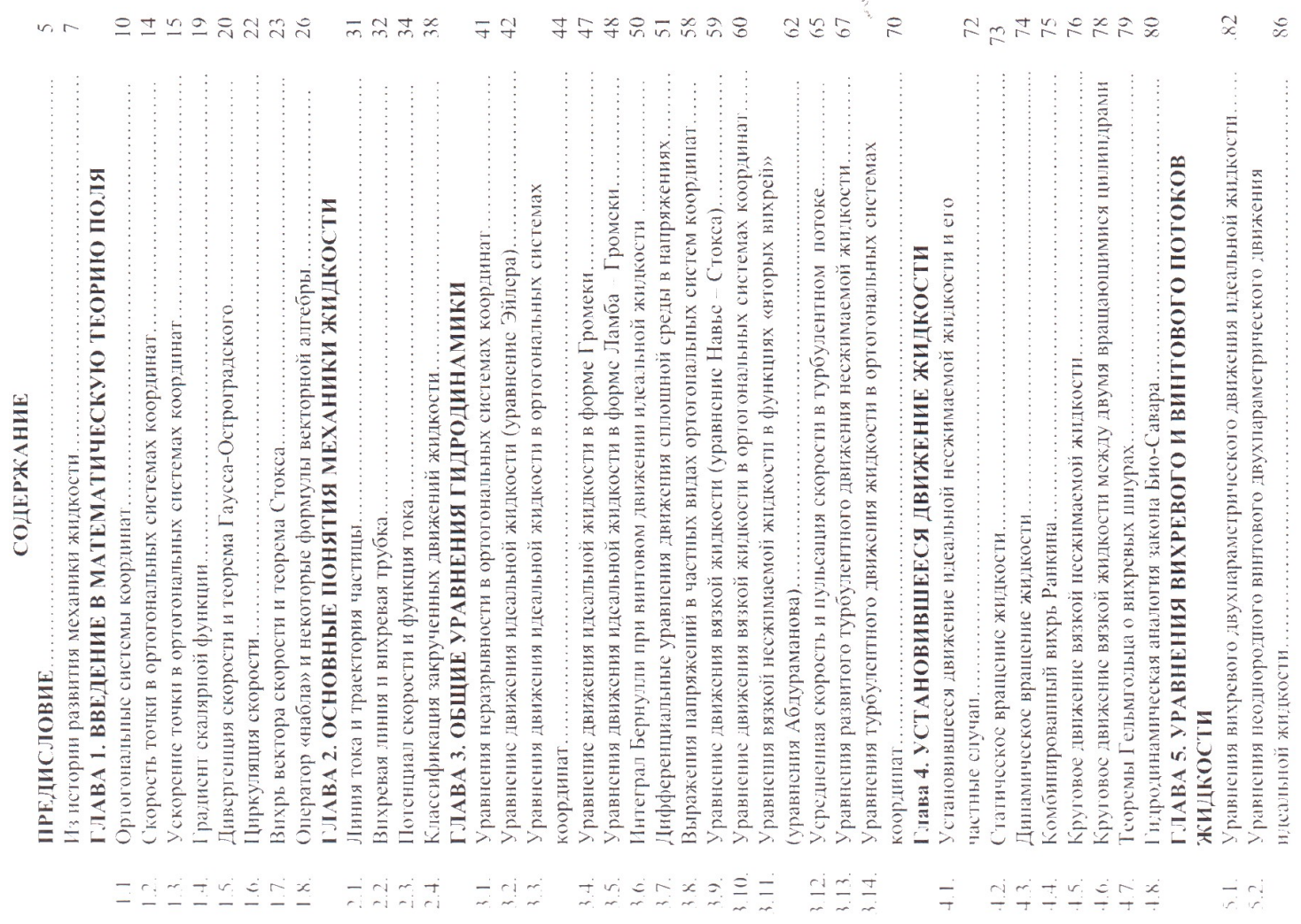

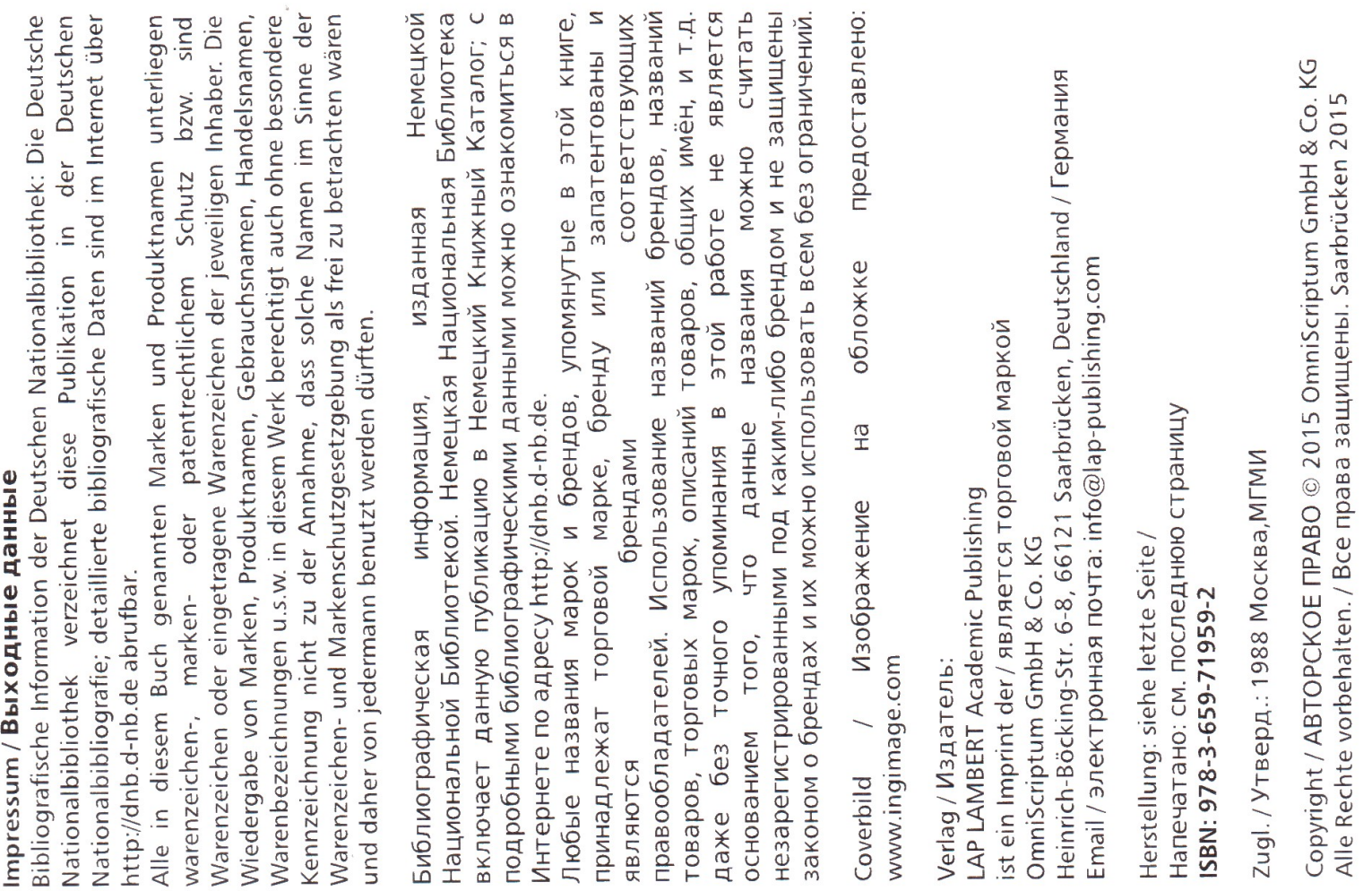




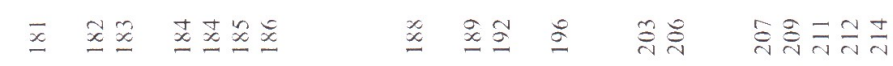

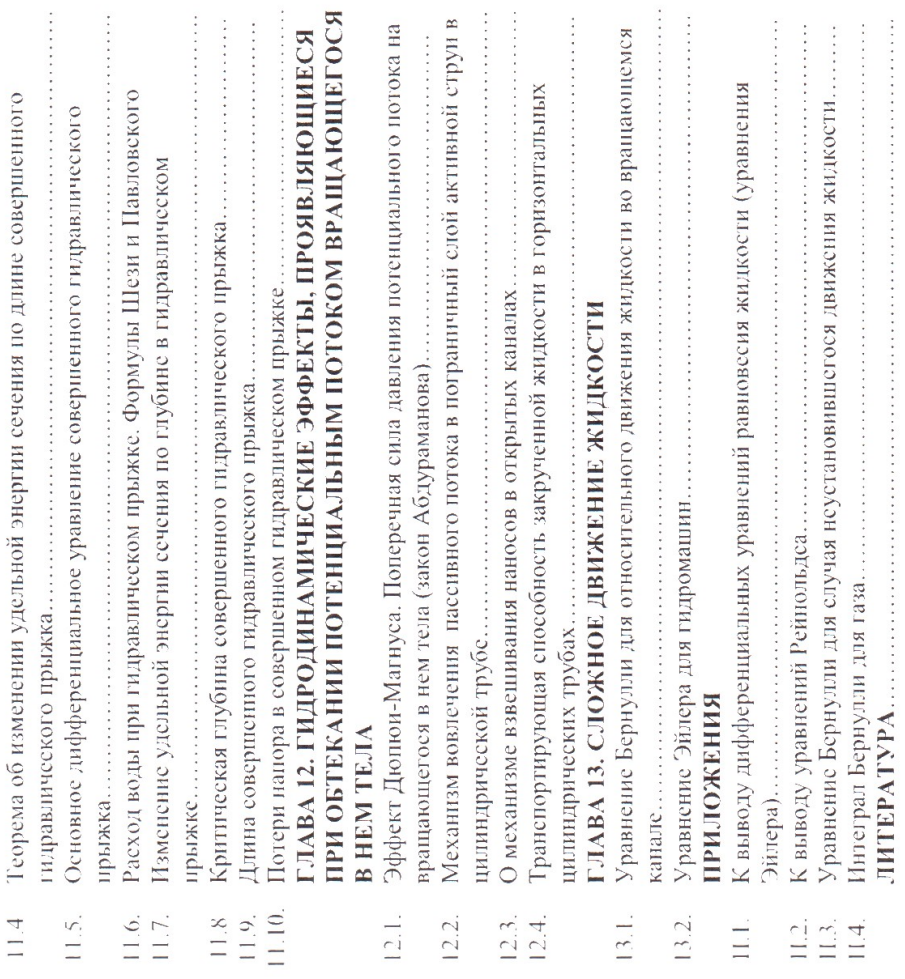

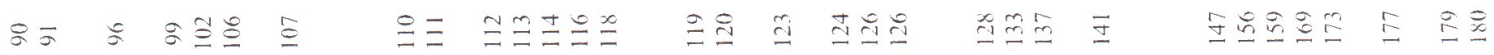

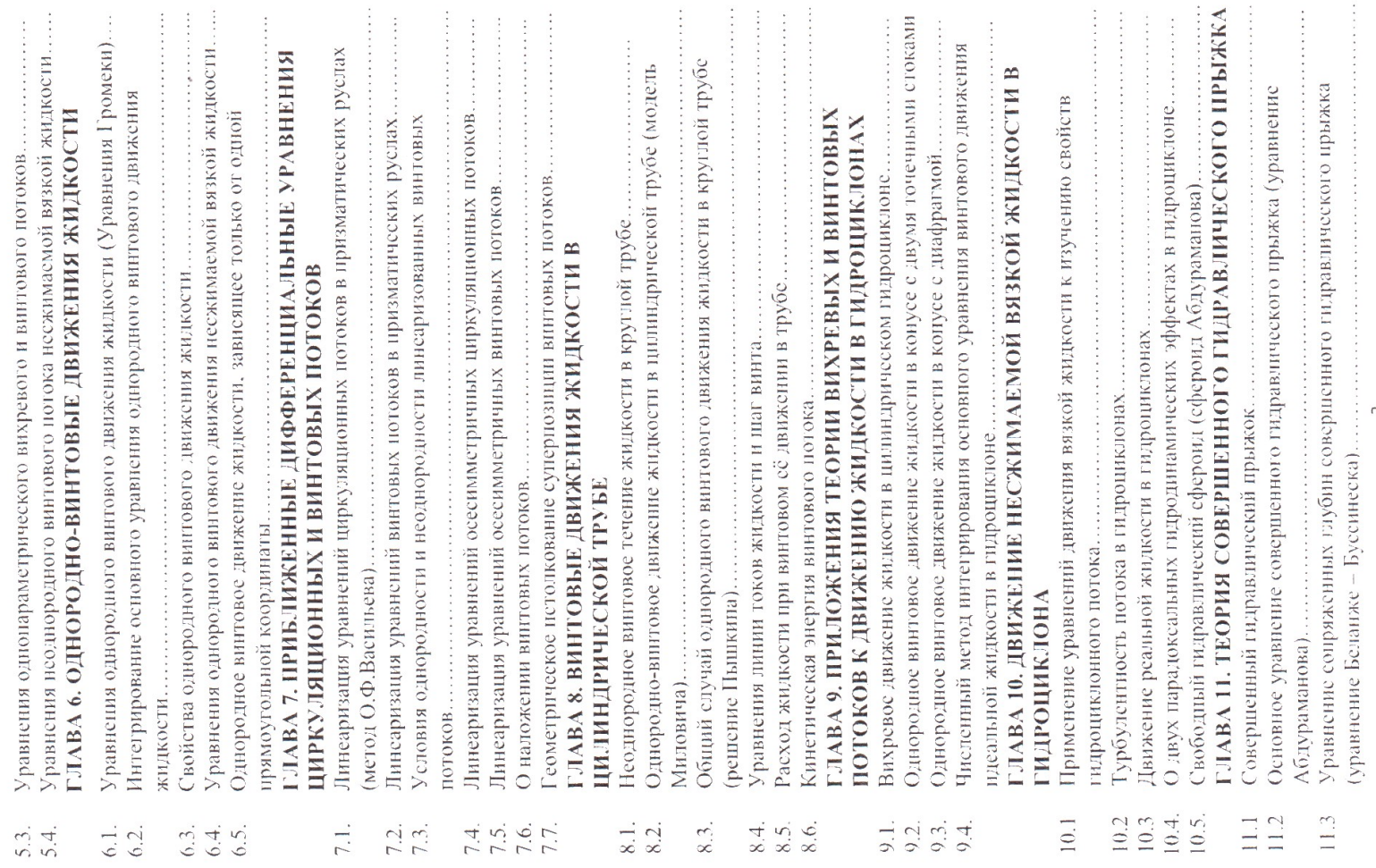

